\title{
Exploration the Needs of Nursing Care of Drugs Addiction Service Institutions in Indonesia
}

\author{
Herni Susanti ${ }^{1 *}$ (D) Ice Yulia Wardani ${ }^{2}$ D, Nurlaila Fitriani ${ }^{3} \mathbb{D}$, Kurniawan Kurniawan $^{4}$ (D) \\ ${ }^{1}$ Department of Mental Health Nursing, Faculty of Nursing, Universitas Indonesia, Depok, Jakarta, Indonesia; ${ }^{2}$ Department of \\ Mental Health Nursing, Faculty of Nursing, Universitas Indonesia, Depok, Jakarta, Indonesia; ${ }^{3}$ School of Nursing, Faculty of \\ Health Sciences, Universitas Muhammadiyah Surakarta, Surakarta, Indonesia; ${ }^{4}$ Department of Mental Health Nursing, Faculty \\ of Nursing, Universitas Padjadjaran, Sumedang, Indonesia
}

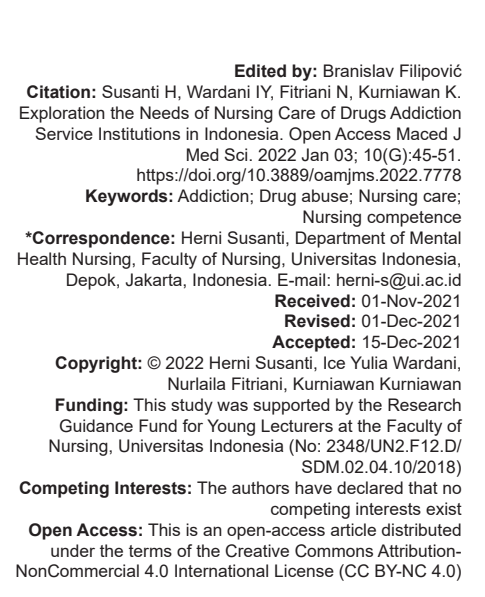

\section{Abstract}

BACKGROUND: Nurses as a care giver play an important role in managing addicts. The implementation of quality care needs to be supported by the availability of services and appropriate guidance to care providers. In Indonesia, what is available is a general guide for all healthcare professionals.

AIM: This study is to explores nurses' and health professionals' views about the need of nursing care to care for drug addiction clients.

METHODS: This study used qualitative descriptive study. The data collection used in depth interviews. The study involved 10 nurses and 10 health profession recruited from the three government centers of addiction services in the capital city of Indonesia. The analysis of the data using thematic analysis.

RESULTS: There were four themes in this study such as gray area between nurses and other health workers in handling clients, the role of drug addiction nurses, challenges and strategies in caring for addiction clients and hopes.

CONCLUSION: Nursing staff must have the knowledge, attitudes, and special skills to perform their duties. Having a mental health nurse in a drug addiction service facility should be seen as a step toward solving the Indonesian drug addiction nursing dilemma. Good guidance and training should be provided to caregivers of drug addiction services to improve their knowledge, skills, abilities, and behaviors in dealing with drug addiction.

\section{Introduction}

Worldwide, it recorded that around 270 million people in the age range of 15-64 years have used psychoactive drugs in the previous year. About 35 million people are estimated to have experienced drug abuse. As a result, around 0.5 million people die each year [1]. According to the National Survey on Drug Use and Health, 19.7 million American adults (aged 12 and older) struggled with a substance use disorder in 2017. Nearly $74 \%$ of adults with a substance use disorder in 2017 worked with a substance use disorder-alcohol use [2]. In 2016 the Indonesian National Narcotics Agency reported that drug users increased. In 2014, there were 4.1 million people, and in 2015 there were 1.8 million people, bringing the total number of drug users in 2015 to 5.9 million people. 5.9 million Indonesian children out of 87 million children reported to be abusing drugs- -1.6 million are drug dealers [3].

The Drug Dependent Hospital (RSKO), located in Jakarta, Indonesia, as a drug addiction service centers, reported that in 2016 there were 669 visits from 647 visits in 2015 to the Emergency Unit due to drug problems [4]. The increasing number of drug users will also cause an increase in the need for treatment and rehabilitation, especially for chronic drug addiction clients [5]. Clients with this chronic problem need more extended assistance from people around them to meet their basic needs. If they cannot meet their basic needs at home, families generally seek care assistance at various institutions that provide nursing services [6]. At present, especially in Indonesia, services are only found in a few institutions (RSKO, National Narcotics Agency, several mental hospitals, health centers) and have not been evenly distributed throughout Indonesia. The limited institution of drug addiction handling services has resulted in many clients not receiving treatment services, so they are vulnerable to recurrence, further aggravating the situation.

The nurse plays a key role in carrying out the handling of the addiction client. Nursing care starts from the assessment, determination of diagnosis, planning for interventions, implementation, and evaluation; nurses help, support and provide education to clients and families about how to live life without 
drugs after undergoing treatment and rehabilitation. In each emergency department, detoxification, and rehabilitation room, the nursing care is essential even though outpatient, both in psychiatric hospital-based units and community [7]. The implementation of quality care needs to be supported by the availability of services and appropriate guidance for care service providers. At present, in Indonesia, what is available is a general guide for all health workers [8].

The impact of this, among others, causes nurses to experience uncertainty. The results of researcher interviews with ten nurses in various addiction services institutions found that nurses carrying out their duties are complex and confused when handling clients. Some nurses interviewed said they also experienced difficulties and obstacles when doing service in the community, not only at the hospital. Hence, it needs to be identified whether existing nursing care services meet the needs of their intervention. Based on this, it is essential to explore nursing care needs for drug addiction clients that involve nurses and other health workers. The general objective of this study is to explore the need for addiction nursing care based on the nurse's and other health workers perspective.

\section{Methods}

This study was a qualitative study with detailed interviews with 10 nurses, 4 doctors, 2 psychologists, 2 counselors, and 2 social workers. Sampling was the sampling method of interest. Selection criteria for participants with professional experience in substance abuse agencies and a minimum working time of 1 years. In all drug addiction departments, this is a research venue with 34 nurses.

The research site used a government agency that is a service center for addiction in Indonesia.

\section{Data collection}

Researchers used a semi-structured and detailed interview to investigate the outlook for nurses and health workers caring for addiction clients in Indonesia from May to September 2018. Interview activities were conducted directly by first obtaining informed consent and seeking permission to record their voice during the interview. The average interview time was between 40 and $60 \mathrm{~min}$. The tools used in this study were researchers as lead tools, tape recorders, mobile phones, semi-structured interview guidelines, and field notes. The interview began with building trust between the participants and the interviewer.

\section{Data analysis}

Data analysis in the data analysis of this study, NVIVO 12 (QSR International) software was used to encode and organize the data obtained from the participants' estimates and observations. Evaluation of interview results followed a thematic approach. These phases include (1) learning about the data, (2) generate initial code, (3) search for a topic, (4) check the topic, (5) define and name the topic, and (6) create a report. To improve the quality and transparency of reports associated with study results, researchers have applied the qualitative research reporting criteria standards for reporting qualitative research.

\section{Ethical clearance}

The Helsinki World Medical Association was used for this study (World Medical Association, 2013). Participants have the right to withdraw freely from the study. Participants do not know if they will answer offensive questions. In addition, researchers maintained privacy throughout the interview. All recorded data are anonymized by encryption according to P1P15. Participants in this study are volunteers, and there is no physical or mental harm to them in this study. This study was approved by the Nursing Ethics Board on Ethics Committee of the Faculty of Nursing, University of Indonesia, with number N0.287/UN2.F12 D/HKP.02.04/2018.

\section{Results}

\section{Theme 1: Gray area between nurses and} other health workers in handling clients

This first theme consists of two categories namely nurses' dilemmas in nursing actions and overlapping nursing actions with other health workers.

Table 1: Characteristic of participants

\begin{tabular}{|c|c|c|c|}
\hline ID & Profession & Gender & Length of work (year) \\
\hline $1 \mathrm{~A}$ & Nurse & $\mathrm{F}$ & 4 \\
\hline $2 \mathrm{~A}$ & Nurse & $\mathrm{F}$ & 17 \\
\hline $3 \mathrm{~A}$ & Nurse & $\mathrm{F}$ & 14 \\
\hline $4 \mathrm{~A}$ & Nurse & $\mathrm{F}$ & 1 \\
\hline $5 \mathrm{~A}$ & Nurse & $\mathrm{F}$ & 11 \\
\hline $6 \mathrm{~A}$ & Nurse & M & 5 \\
\hline $7 \mathrm{~A}$ & Nurse & M & 8 \\
\hline $8 \mathrm{~A}$ & Nurse & M & 5 \\
\hline $9 \mathrm{~A}$ & Nurse & $\mathrm{F}$ & 6 \\
\hline $10 \mathrm{~A}$ & Nurse & $\mathrm{F}$ & 3 \\
\hline $11 \mathrm{~A}$ & Doctor & $\mathrm{F}$ & 18 \\
\hline $12 \mathrm{~A}$ & Psychologist & $\mathrm{F}$ & 7 \\
\hline $13 \mathrm{~A}$ & Social Worker & M & 13 \\
\hline $14 \mathrm{~A}$ & Peer Counselor & M & 7 \\
\hline $15 \mathrm{~A}$ & Peer Counselor & M & 16 \\
\hline $16 \mathrm{~A}$ & Doctor & $\mathrm{F}$ & 9 \\
\hline $17 \mathrm{~A}$ & Social Worker & M & 26 \\
\hline $18 \mathrm{~A}$ & Doctor & M & 3 \\
\hline $19 \mathrm{~A}$ & Doctor & $\mathrm{F}$ & 3 \\
\hline $20 \mathrm{~A}$ & Psychologist & $\mathrm{F}$ & 10 \\
\hline
\end{tabular}
characteristic of the participants. 
Nurses' dillemmas in nursing actions

The following are the results of interviews with participants:

"So, I act according to what is here, I doubt the validity of my actions. Yes, confused too, this is wrong or right" (P1) anyway." (P5)

"... not yet fully know what the soul nurse does workers

Overlapping nursing actions with other health

This topic was based on statements from almost all participants. In general, the majority of nurses who took care of patients feel overlapping nursing actions with health workers.

The following are the results of interviews with participants:

"...The nurse specifically fills up on Thursday. Wednesday is a counselor, Monday is a doctor, Tuesday is a psychiatrist. It contained all health education..." (P1)

"...if the role of nurses is still minimal yes because some are taken over by other health workers"ș(P5)

"...But when did the nurses have it, yes we also took many of the counsellors" (P3)

“...yes I'm confused. I also ended up continuing with it, finally studying its readiness, I developed it too, but eventually, it went into the counselor's actions, so the gray area" (P2)

"So far, it might be considered that it's the counselor's domain, so we don't take it, you know. If it was me, my business ended up being more discopated - what's more, the term is getting more feedback, then I have treatment, it doesn't mean l'm reducing my work" (P18).

\section{Theme 2: The role of drug addiction}

\section{nurses}

The role of a nurse in a drug addiction counseling center can be divided into two roles: a nurse in the detox room and a nurse in the rehabilitation room.

Nurses play an important role in the detoxification room

The results of this study show that the role of addiction nurses is very important in caring for addicts. Nurses play an important role in detoxifying clients. Hence, she acts as a caregiver, where she is the first contact for the client.

The nurse has a role in fulfilling the needs and handling the client's complaints as explained in the sentence below:
"If the detox needs are met, handled complaints" (P2)

"The role of nurses there is more to assist and meet their needs" (P1)

"If it is a nurse that is when she goes through a crisis like that. However, it is the counsellor's job, if not for nurses, if it is for counselling. Unless this resident is related to illness, we will counsel him to a nurse; later the nurse will proceed to a general practitioner." (P 14).

The role of the nurse becomes very important in the rehabilitation room

The following statement describes this role:

"Some also want to commit suicide, well, if those who lock themselves in a room, we motivate them, to interact with the environment, take part in program activities" (P2)

"We will motivate while talking only so that he is not tense, what is it that we just talk" (P7)

"And if for the patients themselves we still provide education or we are here so that you are at the hospital you should study like this, just think of it as your own home, so do you care or be organized" (P9)

"How does he synergize with addiction counsellors, because both of them have the same pattern care the addiction counsellor is also upbringing, right? When do we know to judge someone, manipulative or not, when do we know that he or she needs support" (P16).

\section{Theme 3: Challenges and strategies in caring for addiction clients}

Caring for addicted clients requires ability and strategy because clients with addiction have the characteristic of being manipulative. The client's manipulative attitude is not easy to handle, so nurses in carrying out their duties require special skills and strategies. There are two categories on this theme, namely improving therapeutic communication and becoming a sharing friend.

\section{Improving therapeutic communication}

Therapeutic communication is the key that nurses must have in carrying out their profession. The strategy taken to establish therapeutic communication with clients is by listening well, humor, communicating with no judge, and maintaining client privacy.

"So, we don't always blame them when communicating" (P4)

"Not patronizing giving out, judging like a b $c$, advising. We here help think alone determines the pros and cons" (P3) 
"We just prepare it so I just use it so I try to listen to what he complains" (P4)

"Start from the beginning, and we don't judge, discriminate, or blame" (P2)

"So we just tell stories like friends while joking but interrupted - we caught it so finally all came out why did he use, with whom, how much he used for what it was right out chatting - the chat became familiar so it wasn't too direct we detailed directly" (P4)

'First, trust, trust here is the most important thing, we don't divulge the secret to friends, or to other officers" (P2)

"The obstacles come from residents, who don't want to be honest, don't open up, they defend themselves, they're not honest when they're sick, light is heavy, heavy is light." (P15).

\section{Nurses' becoming a sharing friend}

The results of this study indicate that nurses use the method of sharing with clients. Establish closeness by being friends and providing security for clients in the professionalism of the work of nurses. Closeness with clients is one good way to get the information needed by nurses in the assessment to get accurate data from clients

"The role of the nurse there is sharing because I think that's the main thing" (P2)

"If the resident activities are mixed., (P3)

"We are adjusting here, we are friends with them. we share, what we feel until we feel like that right" (p4)

"I know that the nurses with problems here are always nurses who don't have compassion" (P16).

"Nursing care documentation is a pile of gibberish like this. I look at it some times. well, finally, when I open the results of the documentation, it's written from the patient arriving until.so it is like the answer is routine, "the patient is calm" Even though it should be a minimum of 1 week, an article writes how the output is obtained after 1 week. 1 week what output from detox did he get. Now he has been treated, and his emotions are so, what output did he get.oh yes, the emotion is gone, well it should be written..." (P1).

\section{Theme 4: Hopes}

Expectations found in dealing with the situation of implementing addiction nursing services include specific guidelines for nurses in carrying out nursing care and special training for nurses in addiction services. nursing care
During this study, nurses complained that there were no specific guidelines for nurses in carrying out their duties in addiction services.

Nurses only follow general guidelines for all health workers. The following statement describes their expectations

"Oh, if I did nursing documentation, in my opinion, if I think that there are guidelines, then we are not too problematic" (P4)

"What we ask, what we do, is written." (P1)

"This study is not general enough, the point is lacking. the standard means there is." (P6)

"In medicine, there is such a thing as optional education, for example, drugs. But there is no nurse yet. So, when they enter the service, they are placed here, they are confused...there is no drug knowledge" (P16).

\section{services}

\section{Special training for nurses in addiction}

In addition to the absence of guidance, nurses also complain about the lack of special training for addicted nurses to improve their abilities and knowledge in carrying out nursing care. Special training is needed to support the work of nurses in addiction services. As illustrated in the following statement:

"Yes, according to the standard, then according to the existing training, training from friends who have participated should be able to share with us" (P7)

"We also need other training, other skills. We also want to be able to assess it like a doctor, yes, with the addition of our assessment ability, we can ease each other's tasks" (P8)

"For the specific training that is needed, what should the nurses here be able to handle the resident, what is training?" (P7)

"But what they have to do is have a book, so in that book, the patient, one patient, will have one book, in that book we will make a need assessment for him" (P16)

"How to manage people like this is emotionally exhausting for sure, but how do we get into their world without them having to be involved with that world looking at the other side, now the science of looking at the user's brain above, looking at the brain of NPS users, this is not too much in the input into the curriculum perhaps from the nurse" (P18)

"Handling this client is a team, it means we have to complement each other eh." (P20)

"I hope the nurse can be more like what is called, closer to the patient, what is the name, not just being in the room all day but being friends, right 
there is a term in the nursing world what is therapeutic communication" (P13).

\section{Discussion}

Based on the results of the survey, the survey has four topics: the gray area between nurses and other healthcare professionals in dealing with residents, the role of nurses in drug addiction, and the care of addicts. It turns out that the focus is on challenges, strategies and communication in. Caregiver strategies, expectations and hopes.

\section{Theme 1: Gray area between nurses and other health workers}

This study indicates that nurses' still find grey areas between nurses and other health workers in providing services to clients. The study found that nurses and other health workers take the same action on the client. One reason for this is collaboration between health workers is not optimal; knowledge and skills are not qualified. Lack of knowledge about drug addiction can cause weak ability and skills in providing services [9], [10]. Nurses need knowledge, attitudes, and skills to be independent and become partners with other health workers in carrying out their duties [11].

Nurses experience a dilemma where the implementation of addiction services becomes ambiguous and overlaps due to unclear tasks and roles between nurses and other health workers [12]. This ambiguity then causes confusion and even stress [13]. Nurses in addiction services also experience overwhelmed in caring for clients. Although clients do not need total care, this condition is one of the challenges nurses can work optimally in drugs addiction services. Based on this, it can be concluded that it is essential for nurses to improve their knowledge and skills in addiction services. Besides, there is a need for a clear duty on the role of each health worker so that it is easy for nurses and other health workers in the order of drugs addiction services to collaborate and divide work areas.

\section{Theme 2: The role of the nurse}

This study indicates that the role of nurses in addiction services is to be an educate, motivate, advocate, problem solve, and be a good listener. Two wards are at the core of the nurse's role while caring for addicted clients; the first is the detoxification room, and the second is the rehabilitation room. The results of this study show us that nurses play a significant role in the detoxification room. The nurse is a good listener, accompanies and meets the needs of clients during the detoxification process. The presence of a nurse as a provider of nursing services is an antidote to client anxiety during detoxification. The client's will leave the habit of consuming alcohol by taking detoxification steps requires support and reinforcement [14]. Longterm care during detox focuses on physical problems, but it is essential to assess and listen to psychological complaints. Present themselves fully as professional nurses to achieve a relationship of mutual trust and therapeutic communication so that clients get comfort in nurses.

The nurse acts as an educator for the client who is undergoing a rehabilitation program. Provide education about worship when attending programs and education about the diagnosis experienced by clients and how to manage themselves while undergoing rehabilitation [15]. This study found that nurses gained very little knowledge and did not even know about handling addiction clients. It proves that nurses provide education to patients based on needs with the knowledge they have. Nurses develop strategies in providing knowledge to clients without formal training [9]. The role of addicted nurses is as an advocate for clients. Furthermore, nurses become the main actor in handling and preventing risks due to drug abuse [16].

The role of nurses that have not been found in the results of this study is the role of mental health nursing professionally as a service provider in the form of independent action to improve client comfort. The independent actions of a specialist psychiatrist such as cognitive behavior therapy, behavior therapy, cognitive therapy [17] can be given to control the mind and behavior of clients so they can stop using drugs. They acted independently like this can increase the client's confidence and comfort in participating in the therapy series. Based on the above, it can be concluded that the need for specialist mental nurses in providing mental health services independently to manage the psychological problems of addicted clients.

\section{Theme 3: Challenges and strategies in caring for addiction clients}

Nurses in carrying out their role in caring for drug addict clients encounter many challenges. The method used in dealing with these challenges is how nurses obtain valid data from clients. Nurses obtain valid information by establishing closeness. The closeness of the client nurse can be achieved by increasing the ability to communicate [18]. Good communication by nurses will increase client confidence in nurses in providing services. Communication of client nurses, in this case, is using therapeutic communication as seen in the results of research that nurses do many ways to establish trust with clients [19].

This study indicates that empathy, being friends, listening well, and sharing with addicted clients 
are good strategies for building trust. The nurse's step in fostering trust to establish therapeutic communication is key to getting valid patient data. Given the manipulative addiction client's condition, therapeutic communication is a significant factor in the nurse's success performing her role [20].

\section{Theme 4: Hope}

This study proves that nurses at the addiction service center expect progress in curriculum and guidelines for providing addiction to client nursing care. It is important to highlight because nurses must provide the best service when providing services to clients. The best service is obtained from nurses' sound knowledge and attitude about how to deal with clients. Good knowledge should be given since nurses are still pursuing formal education. Nurses must own particular competencies in handling addiction client problems [21].

Special training mentioned nurses as a need to support the professionalism of service. Nursing care, especially in the rehabilitation room, is done by nurses by relying on work experience while being a nurse in an addiction room. Experience makes them able to handle unique problems due to client manipulative behavior. Even so, nurses still want special training on procedures for handling addicted clients in services based on evidence-based. This study proves that in addiction services, specialized training of nurses to deal with addicted clients both physical and psychological problems is rarely [20].

\section{Conclusion}

Based on the results of this study, it can be concluded that addiction nurses in carrying out their duties must be equipped with knowledge, attitudes and special skills. The presence of a psychiatric nurse in the setting of drug addiction services needs to be considered a step in resolving the dilemma of drug addiction nursing services in Indonesia. Exceptional guidance and training for nurses in drug addiction services must be provided to improve nurses' knowledge, skills, abilities, and behavior in handling addiction clients.

\section{References}

1. World Health Organization. Drugs (Psychoactive). Geneva: World Health Organization; 2019. Available from: https://www. who.int/health-topics/drugs-psychoactive\#tab=tab_1 [Last accessed on 2021 Jul 20].

2. SAMHSA. Key Substance Use and Mental Health Indicators in the United States: Results from the 2015 National Survey on Drug Use and Health. Publication No. SMA 16-4984, NSDUH Series H-51. Center for Behavioral Health Statistics and Quality Substance Abuse and Mental Health Services Administration; 2018. p. 1-97.

3. Murray K. Addiction in Indonesia. Addiction Centre; 2021. Available from: https://www.addictioncenter.com/addiction/ addiction-in-indonesia [Last accessed on $2021 \mathrm{Jul} 22$ ]

4. Pusdatin Kemenkes. Infodatin Pusat Data dan Informasi Kementrian Kesehatan 2017: Narkoba. Anti Narkoba Sedunia 26 Juni 2017; 2017. p. 1-7. Available from: https://pusdatin. kemkes.go.id/resources/download/pusdatin/infodatin/infodatinnarkoba-2017.pdf [Last accessed on 2021 Jul 22].

5. Allen K. Finding nursing's role in worldwide strategies to address today's addictions. J Addict Nurs. 2018;29(2):73-7. https://doi. org/10.1097/JAN.0000000000000227 PMid:29864053

6. Vossius C, Testad I, Skjæveland R, Nesvåg S. The use and costs of health and social services in patients with longstanding substance abuse. BMC Health Serv Res. 2013;13(1):185. https://doi.org/10.1186/1472-6963-13-185 PMid:23692822

7. Munro I, Edward KL. Mental illness and substance use: An Australian perspective. IntJMentHealthNurs.2008;17(4):255-60. https://doi.org/10.1111/j.1447-0349.2008.00541.x

8. Ministry Of Health Republik Indonesia. Buletin Napza. Vol. 1; 2014.

9. St. Marie B. The experiences of advanced practice nurses caring for patients with substance use disorder and chronic pain Pain Manag Nurs. 2016;17(5):311-21. https://doi.org/10.1016/j. pmn.2016.06.001

PMid:27567096

10. Glann JK, Carman M, Thompson J, Olson D, Nuttall C Fleming $\mathrm{H}$, et al. Alcohol withdrawal syndrome: Improving recognition and treatment in the emergency department. Adv Emerg Nurs J. 2019;41(1):65-75. https://doi.org/10.1097/ TME.0000000000000226 PMid:30702536

11. Broyles LM, Gordon AJ, Rodriguez KL, Hanusa BH, Kengor C Kraemer KL. Evaluation of a pilot training program in alcohol screening, brief intervention, and referral to treatment for nurses in inpatient settings. J Addict Nurs. 2013;24(1):8-19. https://doi. org/10.1097/JAN.0b013e31828767ef PMid:24622525

12. Jack HE, Oller D, Kelly J, Magidson JF, Wakeman SE. Addressing substance use disorder in primary care: The role, integration, and impact of recovery coaches. Subst Abus. 2018;39(3):30714. https://doi.org/10.1080/08897077.2017.1389802

PMid:28991516

13. Hercelinskyj G, Cruickshank M, Brown P, Phillips B. Perceptions from the front line: Professional identity in mental health nursing. Int J Ment Health Nurs. 2014;23(1):24-32. https://doi. org/10.1111/inm.12001 PMid:15650662

14. Bové HM, Lisby M, Norlyk A. Scheduled care as a way of caring: A phenomenological study of being cared for when suffering from alcohol use disorders. J Clin Nurs. 2019;28(7-8):1174-82. https://doi.org/10.1111/jocn.14715 PMid:30428140

15. ANA. International Nurses Society on Addictions, Scope and Standards of Addictions Nursing Practice. Maryland: Silver Spring; 2013.

16. Jones $\mathrm{H}$, Arms $\mathrm{T}$. Opioids: Literature findings and recommendations. J Psychosoc Nurs Ment Health Serv. 2018; 56(9):17-24. https://doi.org/10.3928/02793695-20180703-01 
PMid:30168842

17. Brandon AR. Psychosocial interventions for substance use during pregnancy. J Perinat Neonatal Nurs. 2014;28(3):162-9. https://doi.org/10.1097/JPN.0000000000000041

PMid:25062518

18. Beeber LS. Mental health issues and substance use in the United States: Pulling the power levers. J Am Psychiatr Nurses Assoc. 2019;25(1):19-26. https://doi.org/10.1177/1078390318811572 PMid:30406713

19. Liebschutz JM, Lange AV, Heymann OD, Lasser KE, Corey P, Shanahan CW, et al. Communication between nurse care managers and patients who take opioids for chronic pain:
Strategies for exploring aberrant behavior. J Opioid Manag. 2018;14(3):191-202. https://doi.org/10.5055/jom.2018.0449 PMid:30044484

20. Abram MD. The role of the registered nurse working in substance use disorder treatment: A hermeneutic study. Issues Ment Health Nurs 2018;39(6):490-8. https://doi.org/10.1080/01 612840.2017 .1413462

PMid:29370552

21. Compton $P$, Blacher $S$. Nursing education in the midst of the opioid crisis. Pain Manag Nurs. 2020;21(1):35-42. https://doi. org/10.1016/j.pmn.2019.06.006

PMid:31358464 